Stefano ZoIA*

\title{
A new species of Pseudostola from Madagascar (Coleoptera Chrysomelidae)
}

Riassunto: Una nuova specie di Pseudostola del Madagascar (Coleoptera Chrysomelidae).

Viene descritta Pseudostola ornata n. sp. del Madagascar e comparata con le altre specie note del genere. Sono fornite una chiave dicotomica e note sulla tassonomia delle specie di Pseudostola. Sono designati i lectotipi di P. amoena Bechyně, 1949, P. perrieri Fairmaire, 1899 e P. tuberculicollis Bechyně, 1946. La sinonimia P. grandis (Fairmaire, 1901) = P. grandis Fairmaire, 1902, già proposta da Berlioz $(1915)$, viene rivalutata.

Abstract: Pseudostola ornata n. sp. from Madagascar is described and compared with the other known Pseudostola species. A key to species of Pseudostola and taxonomic notes are provided. Lectotypes are designated for $P$. amoena Bechyně, 1949, $P$. perrieri Fairmaire, 1899 and $P$. tuberculicollis Bechyně, 1946. The synonymy P. grandis (Fairmaire, 1901) = P. grandis Fairmaire, 1902, already proposed by Berlioz (1915), is reintroduced.

Key words: Pseudostola, Madagascar, new species, new synonymy, lectotype designations.

\section{INTRODUCTION}

To the present day, the known fauna of Eumolpinae of Madagascar includes nearly 320 species, arranged into 29 genera. The first contribution to the knowledge of this fauna dates back to the first half of the XIX century with the descriptions of Lebisiella pulchella (Klug, 1833) and Colasposoma $(C$.) rutilans rutilans (Klug, 1833). After that, several authors worked on this topic, but the largest part of the known species were described by Bechyně (nearly 190 taxa), Fairmaire (42) and Jacoby (36). Despite these two-centuries studies, the examination of recently collected material proved this fauna as being still largely unknown.

A new species of Pseudostola is here described. Pseudostola is an endemic Malagasy genus which at present includes five other species (amoena Bechyně, 1949, fulvida Fairmaire, 1902, grandis (Fairmaire, 1901), perrieri Fairmaire, 1899, tuberculicollis Bechyně, 1946) which were keyed by Bechyně (1949).

\section{MATERIAL AND METHODS}

The reported length of the specimens is evaluated from the anterior edge of pronotum to the elytral apex, being the head, when it is closely inserted in the prothorax, not visible from the above. The ratio of frons width to eye width, to describe the dimensions of the eyes in relation to the head, is evaluated in frontal view along a horizontal line at a level of the minimum width of the frons and the corresponding widest point of the eye. The dissected aedeagi are glued on a card pinned together with the specimen; the dissected feminine genitalia are preserved in a plastic micro-vial pinned together with the specimen.

The holotype of the new taxon here described is deposited in the collections of the Museo Civico di Storia Naturale "G. Doria” of Genoa (Italy).

The following acronyms are used:

MLcoll - Michael Langer collection (Niederwiesa, Germany)

MSNG - Museo Civico di Storia Naturale "G. Doria" (Genoa, Italy)

SZcoll - Stefano Zoia collection (Milan, Italy)

UAcoll - Ulf Arnold collection (Schöneiche - Berlin)

\section{Pseudostola ornata n. sp.}

TYPE SPECIMENS. Holotype $\widehat{\jmath}$ (MSNG): Madagascar: Andasibe, $950 \mathrm{~m}$ Analamazaotra Forest $18^{\circ} 56.5^{\prime} \mathrm{S}$ 48²4.8'E 31.x-4.xi.2007 L. Friedman [printed white label]; Holotypus Pseudostola ornata n. sp. S. Zoia det. 2019 [printed red label].

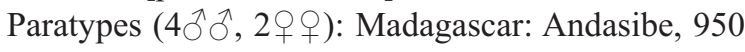

*Stefano Zoia, Via Ponte Nuovo, 109/4, 20128 Milan, Italy. E-mail stefano.zoia@chrysomelidae.it 
m Analamazaotra Forest $18^{\circ} 56.5^{\prime} \mathrm{S} 48^{\circ} 24.8^{\prime} \mathrm{E} 31 . \mathrm{x}$ -

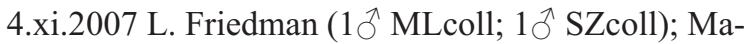
dagascar: Andasibe, $950 \mathrm{~m}$ Analamazaotra Forest $18^{\circ} 46^{\prime} \mathrm{S} 48^{\circ} 24^{\prime} \mathrm{E}$ 31.x-4.xi.2007 A. Freidberg (10 MLcoll); Madagascar Antananarivo prov. Manankazo env. 11.-12.11.1995 Ivo Jeniš leg. (1ㅇ SZcoll); Madagascar [19]95, Tamatave distr., Moramanga env., Dec. 13-17, J. Stolarczyk leg. (1ㅇ UAcoll); Madagascar, 1996, Moramanga distr., Antsahatsaka env. 12.16.12 Jiff Stolarczyk leg. (1 $\overbrace{}^{\Uparrow}$ SZcoll).

Diagnosis. A Pseudostola Fairmaire, 1899 of relatively small size, close to $P$. tuberculicollis Bechyně, characteristic in the antennae with articles 10th and 11th yellow, absence of tubercles on pronotum, elytra brown with large darker spots, peculiar arrangement of the strong white pubescence of dorsum.

DESCRIPTION. Habitus as in Figs 1-2; body length of the $\hat{\delta}$ holotype $2.8 \mathrm{~mm}$, of the $\delta \hat{\delta}$ paratypes $2.7-3$ $\mathrm{mm}$, of the 90 paratypes $2.9-3.0 \mathrm{~mm}$.

Body dark brown to black; head and pronotum dark brown to black with feeble metallic hue, scutellum black, elytra somewhat paler, brownish, with a round blackish spot near base, a large transversal irregular blackish spot in the middle and an irregular blackish spot at the beginning of the apical slope, all spots with not well defined borders and nearly glabrous; labrum ocher brown, mandibles brown with darker apices, palpi ocher yellow; antennal segments 1st-3th ocher, 4th-6th at least partially or more extensively dark brown, 7th-9th nearly completely blackish, 10th11th yellow.

Frons (Fig. 3) moderately large, nearly flat in the middle, with a distinct longitudinal median sulcus; surface with sparse, moderately strong punctation, distance between two adjacent punctures nearly as wide as diameter of a puncture. A white, strong, stiff, relatively long and adpressed pubescence is mainly diffused on frons sides; eyes moderately large, convex, not emarginate at their inner border, space between inner border of eyes in frontal view nearly 2.3 times the width of an eye; ocular sulci absent; clypeus distinct from frons by a transverse impression, with a relatively strong punctation and a few setae at sides, surface with light microreticulation, distal border concave. Penultimate article of maxillary palp nearly as long as wide, ultimate subparallel at base, distally in a frustum of a cone, nearly 2.5 times longer than wide and two times longer than penultimate. Antennae (Fig. 13) slender, nearly reaching the basal third of elytra. Antennomeres slender, 7th-11th distinctly widened, 8th10 th with a pecten of short setae at distal edge. Length of antennomeres of left antenna of $\widehat{\partial}$ holotype, in $\mathrm{mm}$ : $0.19-0.16-0.19-0.23-0.21-0.18-0.22-0.19-0.18-0.17-$ 0.25 ; length/width ratio: $1.9-2.4-3.9-4.6-3.6-3.1-2.4-$ 1.9-1.8-1.7-2.8.

Pronotum transversally strongly convex, a little bulging in the middle, distal edge slightly produced frontward and dorsally flattened; pronotum nearly 1.7 times wider than long $(0.84 \times 1.44 \mathrm{~mm}$ in holotype), maximum width slightly before mid-length; base bordered throughout, border moderately wide and flat; base a little wider than distal edge; distal edge not bordered; sides of pronotum, as seen from above, nearly regularly bent throughout, bordered, the border thin, with some traces of indentations bearing very small hairs; surface with moderately strong and irregularly arranged punctation, distance between two adjacent punctures smaller than diameter of a puncture; surface between punctures smooth; pubescence white, strong, stiff, relatively long and adpressed, white thin setae are present among the stronger pubescence mainly near the distal edge of pronotum, pronotum nearly glabrous on a wide transversal line on discus. Corners of pronotal base with a small tooth bearing a seta; setal insertion of distal corners of pronotum slightly above the level of lateral margin.

Scutellum semi-oval, nearly wide as long, smooth, with a few punctures.

Surface of hypomera smooth, lightly plicate along the outer border, with moderately strong punctures and a white, relatively long pubescence. Distal margins of proepisterna slightly convex and a little produced frontward, hardly separated from edge of prosternum by a fine border. Prosternum nearly so long in the middle as wide between procoxae, distal edge regularly concave, surface nearly flat, strongly punctured and with a long white thin pubescence. Ventral side of body with sparse and thin hairs present on meso- and metasternum and on abdominal sternites.

Mesoventrite a little longer than wide between mesocoxae, with a fine punctation and relatively long thin pubescence; mesocoxae a little less spaced than procoxae; mesoepimera smooth, with a moderately strong punctation and white pubescence. Metaventrite at middle nearly so long as the space between procoxae, with a very light punctation, smooth; metacoxae 

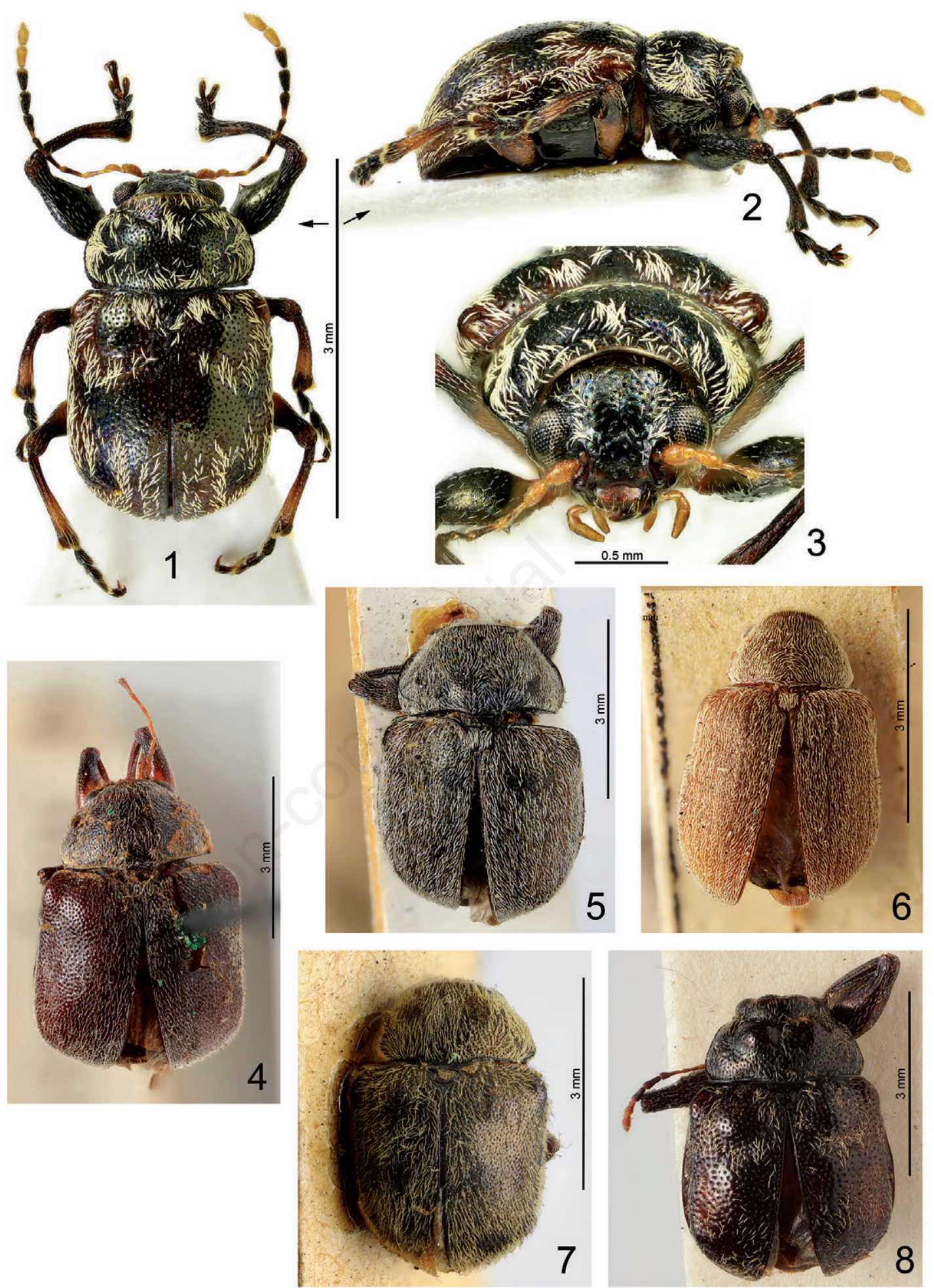

Figs 1-8. 1 - Pseudostola ornata n. sp., holotype, dorsal view; 2 - idem, lateral view; 3 - idem, head; 4 - P. amoena, lectotype; 5 - P. grandis, syntype; 6 - P. fulvida, holotype; 7 - P. perrieri, lectotype; 8 - P. tuberculicollis, lectotype. 
a little more spaced than mesocoxae; metathoracic episterna tapering to rear, nearly 4.5 times longer than wide, punctate and with a white pubescence.

Elytra convex, 1.1 times longer than wide (in holotype: elytral length in dorsal view $2.0 \mathrm{~mm}$, distance from base of scutellum to elytral apex $2.3 \mathrm{~mm}$; width at humeri $1.68 \mathrm{~mm}$, maximum width $1.74 \mathrm{~mm}$ ); elytral sides a little widening from humeri to about two thirds of their length, then regularly bent till apices; apices in a slightly acute angle. Elytral punctation stronger than on pronotum, irregularly arranged, impressed on whole surface, distance between two adjacent punctures on average shorter than diameter of a puncture. Elytral surface smooth, shining, with white, strong, stiff, moderately long and adpressed pubescence arranged as in Fig. 1; sub-basal impression moderately deep, between this and the elytral base a moderately raised basal callus is present; humeri round, smooth, in large part glabrous, covering the lateral border of elytra in dorsal view. Elytral borders thin, hardly visible in dorsal view below the humeri, gradually tapering to rear. Epipleura glabrous, wide and punctured at base, gradually tapering to rear, with a series of punctures along the inner border.

Metathoracic wings fully developed.

Legs relatively long; profemora swollen, mesoand metafemora moderately swollen, each with an evident acute median tooth; protibiae longer than mesoand metatibiae, particularly in $\widehat{\partial} \hat{\jmath}$, bent inwards, mesotibiae slightly bent inwards, metatibiae straight, meso- and metatibiae not emarginate near the apex. Pro-, meso- and metatarsi widened in male (Fig. 14). Claws wide apart, appendiculate, basal tooth reaching nearly mid length of the claw.

Aedeagus as in Figs. 9-10; tegmen (Fig. 11) wide, moderately sclerotized, distally with short lateral arms hardly embracing the sides of median lobe; ventral sclerite of sternite IX as in Fig. 12.

Spermatheca as in Fig. 15 with spermathecal gland twice as long as the spermathecal length; vagina without evident sclerotizations; styli very short, sclerotized, spiculum gastrale thin and long (Fig. 16).

DeRIVATIO NOMINIS. From the Latin ornāta (adorned), referring to the pattern of white setae on the dorsum.

Comparative notes. Pseudostola ornata $\mathrm{n}$. sp. recalls $P$. tuberculicollis in the convexity of the pronotum which is transversally impressed and flattened near the distal edge and in the evident sub-basal impressions of the elytra; it differs in the smaller size, absence of pronotal tubercles, more evident dark spots on the elytra, finer and differently arranged pubescence of dorsum. It differs from all known Pseudostola species in the smaller size, glabrous dark spots on the elytra, stronger and differently arranged white pubescence of dorsum.

P. ornata n. sp. can be inserted as follows in the key proposed by Bechyně (1949) (reported body size of $P$. fulvida is modified based on the real body length of the type specimen):

1 (10) Pronotum without tubercles on disk.

2 (7) Elytral pubescence uniformly diffuse, elytra without spots of different color.

3 (4) Dorsum without metallic hue, antennae completely testaceous, antennomeres greatly lengthened; pronotum without transversal impression on the distal third; length $5.5 \mathrm{~mm}$. ..amoena Bechyně (Fig. 4)

4 (3) Smaller size; body more or less metallic; antennae reddish with antennomeres 9th and 10th blackish.

5 (6) Larger size, on average (3.5-4.5 mm); legs mostly metallic; antennomeres 7th-10th black; pronotum with a deep transversal impression on the distal third. grandis (Fairmaire) (Fig. 5)

6 (5) Smaller, on average (2.5-4 mm); legs mostly reddish, antennomeres 8th-9th or 5th-10th black, pronotum without evident transversal impression on the distal third....

...fulvida Fairmaire (Fig. 6)

7 (2) Elytral pubescence more or less arranged in longitudinal stripes, leaving glabrous areas which are darker in color.

8 (9) Elytra reddish with metallic spots, pubescence fine, arranged in hardly distinct longitudinal stripes which are more or less discontinued; pronotum with a deep transversal distal impression; antennomeres 8th-9th or 5th-10th black; length $2.5-4 \mathrm{~mm}$.....

perrieri Fairmaire (Fig. 7)

9 (8) Elytra dark brown with blackish spots, nearly without metallic hue; pubescence strong, stiff, white, arranged on the elytra in more evident longitudinal stripes leaving the darker spots of elytra glabrous; pronotum with a moderately deep transversal distal impression; last two an- 

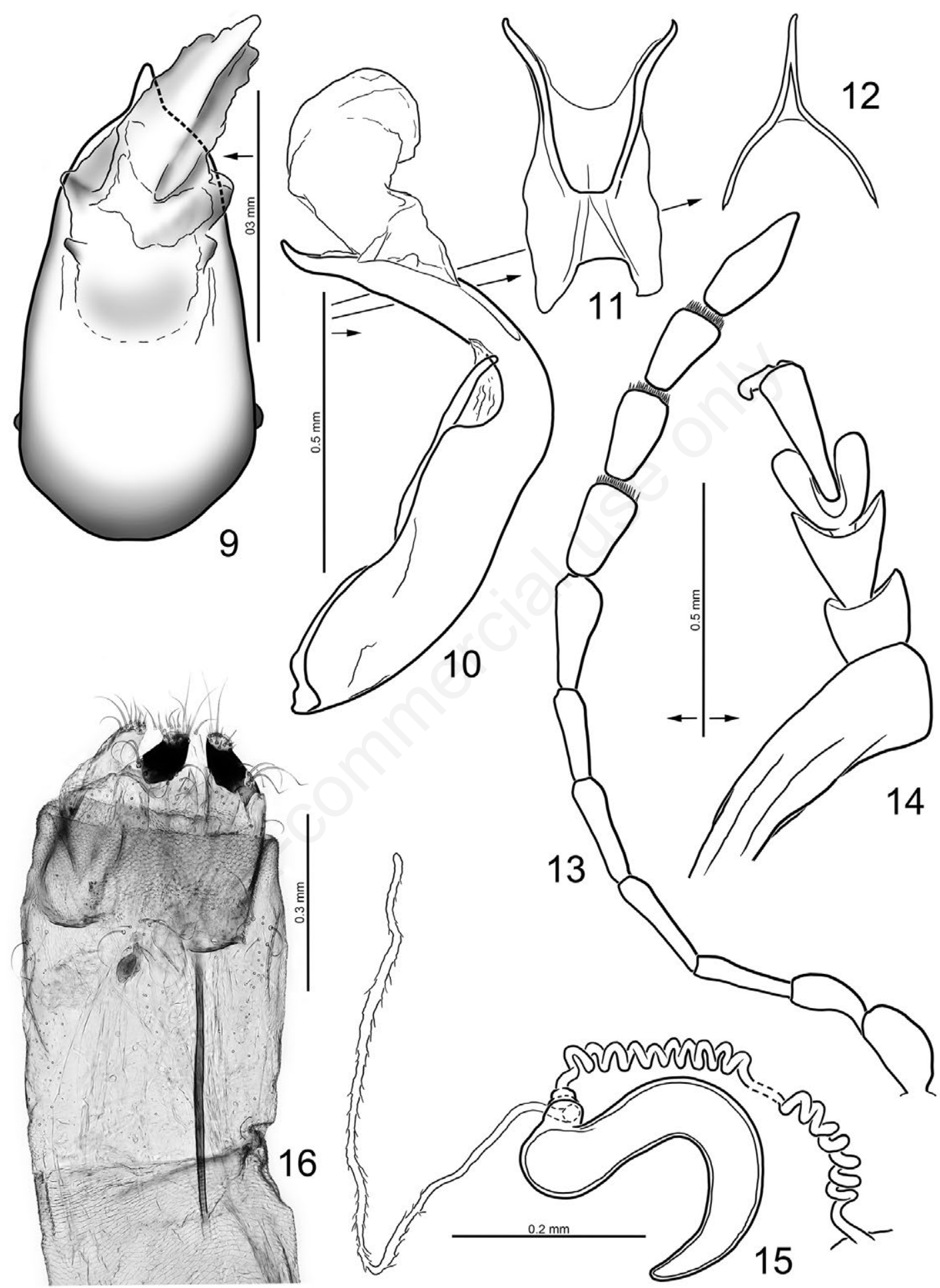

Figs 9-16. Pseudostola ornata n. sp.: 9 - aedeagus, dorsal view (holotype); 10 - idem, lateral view; 11 - idem, tegmen; 12 ventral sclerite of sternite IX (holotype); 13 - idem, left antenna; 14 - idem, left protarsus; 15 - spermatheca (paratype); 16 idem, genital segment. 
tennomeres yellow, strongly contrasting in color with antennomeres 8th and 9th; length 2,7-3 mm ornata n. sp. (Fig. 1)

10 (1) Disc of pronotum with two evident tubercles, transversally placed; dorsum metallic, elytral pubescence irregularly arranged, leaving large glabrous areas; length $4.5-5 \mathrm{~mm}$ tuberculicollis Bechyně (Fig. 8)

\section{Pseudostola amoena Bechyně, 1949}

Bechyně (1949) did not mention the number of examined specimens in the description of this taxon, but he likely examined only one. The examined specimen in the collection of the National Museum, Museum of Natural History, Praha (labelled: Majunga [printed white label]; collection Achard / Mus. Pragense [printed white label]; Typus [printed red label]; Pseudostola TYPE / amoena $\mathrm{n}$. sp. $\mathrm{m}^{*}$ [handwritten white label]; 1947 Det. J. Bechyné [printed and partially handwritten white label]) is here designated as Lectotype of this taxon (Fig. 4).

Pseudostola fulvida Fairmaire, 1902

Fairmaire examined a single specimen which was collected at the "Environs de Suberbieville". The holotype in Fairmaire's collection (Musée national d'Histoire naturelle, Paris) bears the labels: Madag. Perrier [handwritten white label]; Pseudostola fulvida Frm Madag. [handwritten white label]; Type [printed white label with red ink]; Museum Paris Madagascar Perrier de la Bathie coll. Leon Fairmaire 1906 [printed blue label] (Fig. 6).

\section{Pseudostola grandis (Fairmaire, 1901)}

Trichostola grandis Fairmaire, 1901: 239.

Pseudostola grandis, Fairmaire, 1902: 265 n. syn.

Pseudostola grandis, Berlioz, 1915: 439 (note)

Trichostola grandis, Bechyně, 1946: 311

Pseudostola grandis, Bechyně, 1946: 311

The species was collected in the "Environs de Suberbieville" (Fairmaire, 1901). Fairmaire did not mention the number of specimens examined. Five syntypes are present in Fairmaire's collection (Musée national d'Histoire naturelle, Paris), one of which is labelled: Pseudostola grandis Frm. Madag [handwritten white label]; Type [printed white label with red ink]; Museum Paris Madagascar Perrier de la Bathie coll. Leon Fairmaire 1906 [printed blue label] (Fig. 5). Four specimens have no type indication.
At least two specimens of the same origin and perhaps from the same series are present in the Musée Royal de l'Afrique Central (Tervuren). Their belonging to the original series of syntypes is doubtful, although they show the same kind of preparation (disposition of legs and antennae and kind of board on which the insect is glued); surely, they were studied and described later as Pseudostola grandis by the same author (Fairmaire, 1902). This description of 1902 so perfectly matches that of 1901 to suspect that its formulation with the taxon name not followed by the author's name could be accidental and introduced by Fairmaire only to correct the genus name (Pseudostola was described by the same Fairmaire in 1899), not to describe a new taxon. Nevertheless, the formulation involves considering the name published in 1902 as available. A comparison of the syntypes of Trichostola grandis with the ones of Pseudostola grandis clearly proves they belong to the same species. A specimen in the Musée Royal de l'Afrique Central (Tervuren) is labelled: Holotypus / Musée du Congo, Madagascar (Perrier) Coll. Clavareau [printed and partially handwritten white label; Type / Madag. Perrier [handwritten white label]; Trichostola grandis Frm J. Bechyné det. 1953 [handwritten and partially printed white label]; grandis Frm [handwritten white label]. The label "holotypus" appears clearly inappropriate and must be eliminated. The two said specimens must be considered as syntypes of $P$. grandis Fairmaire, 1902 and labelled accordingly.

The two taxa were already synonymized by Berlioz (1915), however Bechyně (1946) erroneously re-established the original situation.

Based on examined type specimens and available bibliographic data the synonymy proposed by Berlioz (1915) is here confirmed and reintroduced.

\section{P. perrieri Fairmaire, 1899}

Fairmaire (1899) did not mention the number of examined specimens in the description of this taxon, but he likely examined only one. A single specimen is present in the collection of the Musée national d'Histoire naturelle, Paris (Madagr Suberblle H. Perrier [handwritten white label]; Pseudostola Perrieri Frm. Madag. [handwritten white label]; Museum Paris Madagascar Coll. Perrier de la Bathie 1906 [printed blue label]; Type [printed white label, red ink] Museum Paris Madagascar Perrier de la Bathie Coll. L. Fairmaire 1906 [printed blue label]) and is here designated as Lectotype of this taxon (Fig. 7). 
Reported locality in Fairmaire (1899) is "Vallée de la Betsiboka".

\section{P. tuberculicollis Bechyně, 1946}

Five specimens are mentioned in Bechyně (1946), three of them are in the National Museum, Museum of Natural History, Praha and are distinct in one type and two cotypes by original author's labels. Other two specimens, both labelled as cotype, are in the Natural History Museum, London and in the Musée national d'Histoire naturelle, Paris. I here designated as Lectotype of this taxon the specimen of the National Museum Museum of Natural History, Praha which was originally designed as "type" (Vohé- mar / Madagascar [printed white label]; TYPUS [printed red label]; Pseudostola TYPE m* / tuberculicollis n. sp. [handwritten white label]; 194 [printed white label]; 7 [handwritten white label]; Det. J. Bechyné. [printed white label] (Fig. 8).

Photos of types of these species are also available on the author's website (http://www.chrysomelidae.it/afr_Eum/).

\section{ACKNOWLEDGEMENTS}

My thanks to Michael Langer and Arnold Ulf who provided me a part of the material object of the present contribution.

\section{REFERENCES}

BeChYNĚ J., 1946 - Notulae ad cognitionem Phytophagorum madagascariensium (Col.). Acta Entomologica Musei Nationalis Pragae, 24: 69-81.

BeChyNĚ J., 1949 - Dixième note sur les Eumolpidae malgaches (Col.). Acta Societatis Entomologicae Cechosloveniae, Prague, 46(1-2): 18-25.

Berlioz J., 1915 - Coléoptères Eumolpides des Iles Mascareignes (Mission scientifique de M. P. Carié, 1910-1913). Annales de la Société entomologique de France, 84: 435-458.

FAIRMAIRE L., 1899 - Matériaux pour la faune Coléoptèrique de la région Malgache. $9^{\wedge}$ note. Annales de la Société entomologique de France, 68: 466-507.

FAirmaire L., 1901 - Matériaux pour la faune Coléoptèrologique de la Région Malgache (11e Note). Revue d'Entomologie, 20: $101-248$

FAIRMAIRE L., 1902 - Materiaux pour la faune coléoptérique malgache. 13e note. Annales de la Sociètè Entomologique de Belgique, 46: 236-271.

KLUG J.F.C., 1833 - Bericht über eine auf Madagascar veranstaltete Sammlung von Insecten aus der Ordnung Coleoptera. Abhandlungen der Königlichen Akademie der Wissenschaften zu Berlin, 1 (1832): 91-223, 5 tavv.

ZoIA S., 2018. African Eumolpinae site (Coleoptera Chrysomelidae). World Wide Web electronic publication. http://www.chrysomelidae.it/afr_Eum/[accessed December 2018]. 